\title{
Trust and Information Sharing in Supply Chains
}

\author{
Neda Ebrahim-Khanjari \\ Department of Industrial Engineering and Management Sciences, Northwestern University, 2145 Sheridan Road Room C210, Evanston, \\ Illinois 60208, USA, neda@northwestern.edu \\ Wallace Hopp
Stephen M. Ross School of Business, University of Michigan, 701 Tappan Street, Ann Arbor, Michigan 48109, USA, whopp@umich.edu
}

Seyed M. R. Iravani

Department of Industrial Engineering and Management Sciences, Northwestern University, 2145 Sheridan Road Room C210, Evanston, Illinois 60208, USA, iravani@iems.northwestern.edu

\begin{abstract}
$\mathrm{D}$ rawing on behavioral research, we construct a multi-period model with which to examine the role of trust and other social characteristics in a supply chain. Specifically, we focus on trust building in the context of a salesperson who acts as a representative of a manufacturer and shares demand forecast information with a retailer. The actions of the salesperson affect both her immediate economic gain and her future credibility as determined by retailer's trust. Our analysis reveals that, in such environments, although salespersons of widely varying types (e.g., honest, self-serving, benevolent, loyal) lie some extent about their forecast information, they tend to be trusted in long relationships, provided their forecasting accuracy is higher than that of the retailer. Furthermore, while the presence of a salesperson can improve the profits of both the retailer and manufacturer, there are cost structures under which the manufacturer is better off without a salesperson. Finally, we make the general observation that the appropriate salesperson compensation scheme depends on her social characteristics, and the specific observation that when the salesperson cares for the retailer, the linear compensation scheme commonly suggested in the literature as the optimal compensation scheme for the salesperson is no longer optimal.
\end{abstract}

Key words: supply chain; trust; information sharing; salesperson; social characteristics

History: Received: May 2007; Accepted: April 2011, by Karen Donohue, after 2 revisions.

\section{Introduction}

Since the 1990s, supply chain management has been the subject of considerable research attention. A major focus of this research has been on how to eliminate inefficiencies in the supply chain by coordinating the decisions of suppliers, manufacturers, and retailers. Various forms of contracts and incentives have been proposed for improving supply chain coordination and information sharing (Tsay and Agrawal 2004). However, recent experimental work has found that supply chain members tend to deviate from the optimal decisions suggested by the literature (Bendoly et al. 2006). This suggests that there is something more to supply chain relationships than mere economic coordination. In this article, we suggest that supply chain (or indeed any business) relationships also depend on non-pecuniary issues such as trust and social characteristics.

Non-pecuniary issues are important because, although they cannot be measured and contracted on, they affect businesses. For example, Uzzi (1996) showed in a longitudinal empirical study of suppliermanufacturer relationships in the apparel industry that economic exchange over time becomes rooted in complex relationships that involve economic investment, friendship, and altruistic attachments. Furthermore, there is overwhelming evidence of the importance and impact of successful relationships in business decisions (Anderson and Coughlan 2002). The main question we seek to study in this article is how the non-pecuniary issues of social characteristics and trust between the salesperson and retailer affect the performance of a supply chain.

A specific supply chain activity in which trust and social characteristics are important is forecast information sharing. Although it is well known that forecast sharing can lead to uninformative communication if the incentives of the firms who share their forecast are too different (see Crawford and Sobel [1982] for a game theoretic analysis), there are many situations where collaborative forecasting can improve performance. For example, in a field study of a major automotive manufacturer (see Hopp et al. 
[2010] for details) we found that the dealer and the salesperson (who serves as the representative of the manufacturer) willingly share their forecasts of demand despite the lack of any explicit contract about information sharing. However, almost all of the salespersons we interviewed indicated that the key to success was a trusting and mutually beneficial relationship with the dealers. In this article, we specifically examine the role that trust, length of relationship, and social characteristics of the salesperson and the retailer play in this forecast information sharing mechanism.

Drawing on behaviorial research into the composition and development of trust, we construct a multiperiod model with which to examine the evolution of trust and its impact on the sharing of demand forecast information between a salesperson (for a manufacturer) and a retailer (dealer). In our discrete time model, the retailer and the salesperson make demand forecasts in each period. Depending on the environment, the salesperson's forecast may be more or less accurate on average than the retailer's. Once the forecasts are made, the salesperson recommends that the retailer purchases a specific quantity from the manufacturer. With the salesperson's recommendation, as well as his own forecast of demand, the retailer selects his order quantity and places an order. The order is filled, demand is realized, and the process repeats.

In our model, we assume that the retailer does not know the accuracy of the salesperson's demand forecast except through experience. Furthermore, depending on the personality and social characteristics of the salesperson, the salesperson may have different intentions when she recommends an order quantity to the retailer. For example, the salesperson could be concerned only about her compensation, she could also be concerned about the profits to the manufacturer, or she could be concerned about the profits of the retailer as well. The motives and interpersonal skills of the salesperson, and the social characteristics of the retailer, will influence the extent to which the salesperson is able to gain the trust of the retailer. In our model, the retailer receives recommended order quantities from the salesperson in each period. Because the salesperson's recommendations cannot be taken as objective, the retailer must decide to what extent he should trust the salesperson. The retailer's degree of trust in the salesperson influences the weight he gives to the salesperson's recommendation. Then, after observing the realized demand at the end of each period, the retailer updates his trust in the salesperson. How this is done depends on social characteristics of the retailer. For example, he may be trusting, and gain trust in the salesperson quickly, or he may be skeptical, and be very slow to build trust in the salesperson. In this article, we study how trust and social characteristics of the retailer can influence profits in a supply chain. We also examine whether the retailer's skepticism has any effect on the effectiveness of a salesperson and the conditions under which retailer trust in salespersons is strong enough to allow the salesperson's more accurate forecast to improve supply chain profits.

We also consider the social characteristics of the salesperson by studying various types of salespersons. First, as benchmarks for comparison, we consider a benevolent salesperson, who seeks to maximize the retailer's profit, and an honest salesperson, who always tells the truth. Second, to capture reality, we consider several variations of the self-serving salesperson, who maximizes her own utility. Within the self-serving category, we consider different social characteristics: (i) someone who cares only for her own profit, whom we call a selfish salesperson; (ii) someone who also considers gain and loss of the manufacturer while maximizing her own payoff, whom we call a loyal salesperson; (iii) someone who also considers the retailer's gain and loss while maximizing her own payoff, whom we call a compassionate salesperson; and (iv) someone who considers both the manufacturer's and the retailer's gain and loss while maximizing her own payoff, whom we call a fair salesperson. By examining the behavior of the supply chain with these different types of salesperson, we seek to understand how the social characteristics of the salesperson impacts supply chain performance. In particular, we examine what types of salespersons are beneficial to both the retailer and the manufacturer, and whether a benevolent salesperson whose concern is to increase the retailer's profit.

When salespersons are self-serving, as we expect them to be in many environments, salesperson compensation becomes important. We consider two common compensation schemes that are used in practice, namely (i) a simple linear compensation scheme and (ii) a commission-plus-bonus scheme. The simple linear commission compensation scheme has been shown to be the optimal contract form for a broad range of circumstances provided that the salesperson is risk-neutral (McAfee and McMillan 1987). ${ }^{1}$ We seek to understand how trust and social characteristics interact with salesperson compensation to influence the performance of the supply chain. Specifically, we study how the behavior of the different types of salesperson is impacted by the compensation scheme, and how manufacturers should pay different types of salespersons to maximize profits.

As one would expect, we find that a self-serving salesperson tends to inflate her forecast to manipulate retailer orders. However, because manipulative behavior leads to a degradation of trust, even a self-serving salesperson has incentive to moderate her behavior 
toward honesty. Our results show that to gain and maintain trust of the retailer, the salesperson sometimes deflates her forecast and sacrifices current payoff. Furthermore, we find that while the benevolent salesperson is more trusted by the retailer than the other types of salespersons, she nevertheless tells occasional "white lies" that are meant to correct flaws in the retailer's forecasts. While all salespersons, other than the honest salesperson benchmark, tend to lie, we find that a salesperson whose forecasting accuracy is worse than that of the retailer tends to lie more than a salesperson whose forecasting accuracy is better than that of the retailer. The reason is that a salesperson with poor forecasting accuracy has a very hard time maintaining the trust of the retailer, or gaining it back once she loses it. Therefore, to have any influence at all, a low accuracy salesperson must do whatever she can to gain the trust of the retailer, including recommending orders that are close to her forecast of demand rather than what she thinks are optimal for the retailer. That is, she lies to gain trust of the retailer. Finally, while the retailer is better off trusting a salesperson he knows is benevolent or honest, the retailer is always better off being skeptical when the salesperson is self-serving (even when the self-serving salesperson is compassionate).

In game theoretic studies of a single interaction between the parties in a supply chain, researchers have shown that when the parties have conflicting goals, they rarely share information (see, e.g., Ozer et al. 2011). By contrast our evolutionary model of ongoing relationships where trust is a factor shows that salespersons with good forecasting accuracy tend to be highly trusted by the retailer (i.e., information is shared), even when the salespersons have self-serving motives. Such salespersons can improve the profit of both the retailer and the manufacturer, although this depends on the cost structure of the supply chain and the social characteristics of both the retailer and the salesperson. We also find that the retailer only trusts a salesperson who has better forecasting accuracy than himself. A long salesperson-retailer relationship improves the extent to which trust reflects the salesperson's forecast accuracy, and thus the retailer benefits from longer relationships.

Finally, the salesperson compensation scheme impacts supply chain performance, but the manner in which this occurs depends on the trust and social characteristics involved. We find that a salesperson with a simple commission-based compensation scheme is more trusted than a salesperson with a combination of commission-based and bonus compensation schemes but, interestingly, the latter compensation scheme generates more profit for the manufacturer when the salesperson is compassionate (i.e., cares for retailer's profit). This implies that the simple linear compensation scheme, which has been widely reported in the literature to be optimal, is no longer optimal when the social relationship between the salesperson and the retailer is taken into consideration.

\section{Literature Review}

In this article, we focus on the role trust plays in information sharing within a supply chain. Hence, we first review work on the effects of information in supply chain coordination. Then, we review general definitions of trust and its role in various business relationships. Next, we discuss empirical and analytical results specifically on trust in supply chains. We also review the related literature on behavioral economics and marketing on social preferences.

Information sharing between supply chain members has been shown to be beneficial to both individual members and overall system performance. Cachon and Fisher (2000) showed that combining the manufacturer's and the retailer's forecasts improves the flow of goods in supply chain. Aviv (2001) compared a "local forecasting" supply chain, in which the manufacturer and the retailer maintain separate forecasts, with a "collaborative forecasting" supply chain, in which the manufacturer and the retailer join their forecasting efforts. He showed that "collaborative forecasting" tends to be superior to "local forecasting" because of benefits from diversification of forecasting capabilities. For a detailed literature review of information sharing in supply chains, see Chen (2003).

The concept of trust has been explored by researchers across different disciplines, including economics, psychology, and sociology. One of the earliest studies of trust in interpersonal relationships was by Mellinger (1956). Mellinger defined trust as an individual's confidence in another person's intentions, motives, and sincerity of speech. In the past few decades, researchers have proposed various definitions of trust, consisting of one or more of the following three attributes: (i) benevolence (care for the wellbeing of the other party), (ii) integrity (honesty in words and actions), and (iii) competence (ability and creditability) (Larzelere and Huston, 1980). For additional discussions and definitions of trust; see Rousseau et al. (1998).

Many experimental and field research studies have examined the effect of trust in business relationships. In the context of negotiation, trust between the negotiating parties has been shown to facilitate information sharing (Thompson 1991), reduce uncertainty (Kollock 1994), and increase cooperation (Mayer et al. 1995). Carnevale and Isen (1986) suggested that trust leads to more efficient negotiated agreements because 
it induces reciprocity. Within an organization, trust has been shown to be effective in increasing employee cooperation (Smith et al. 1995). In buyer-seller relationships, studies have suggested that trust increases opportunities for future sales (Crosby et al. 1990) and is fundamental for conflict resolution and sustainable buyer-seller relationships (Ganesan 1994). Trust has also been shown to act as a substitute for legally binding contracts (Zaheer and Venkatraman 1995).

Recently, economists have used trust games to examine the role of trust in investment decisions. Berg et al. (1995) studied a single round trust game in which player A decides how much of the show-up fee to send to an anonymous counterpart player B. The amount of money triples when it is passed. Player B then decides if and how much money to return to player A. The authors found that, in contradiction to the non-cooperation prediction of game theory, player A tends to send money to player B. The authors attribute this trusting behavior to the participants' belief that it is human nature to reciprocate. Moreover, the authors found that the likelihood of player $B$ to reciprocate player A's trusting behavior increases when information on social history (e.g., results on how other individuals behaved in past experiments) is provided.

A number of investment trust games have been derived from the work of Berg et al. (1995). Glaeser et al. (2000) combined trust game experiments with surveys and found that individuals who are closer socially exhibit more trust and trustworthiness behavior. Engle-Warnick and Slonim (2004) extended that study to a multi-stage game where the time horizon can be definite or indefinite. They found that, with inexperienced subjects, the level of trust was the same in the definite and indefinite settings. However, trust in the definite time horizon setting decreases as subjects gain experience in the game. Lastly, Bohnet and Zeckhauser (2004) compared a trust game with a probabilistic decision process. They found that, because of averseness to betrayal, individuals were more willing to take investment risks when the outcome is due to pure chance than when it depends on another player's trustworthiness.

Only recently has research in operations management begun to study the effect of trust. Most of this work has been empirical. For example, surveys of supply chain parties have suggested that building trust improves supply chain responsiveness to market changes (Handfield and Bechtel 2002) and induces cooperation among supply chain members (Terwiesch et al. 2005).

Although analytical work on trust is uncommon, some has been done. For example, Ren et al. (2010) considered a supply chain whose buyer shares his demand forecast with a supplier to facilitate the supplier's decisions in building manufacturing capacity. While the buyer has incentive to inflate the demand forecast in an attempt to ensure future supply, the supplier may respond by under-investing in capacity. The authors showed that, if the relationship is long term, it is optimal for the buyer to report the true forecast to the supplier in order to gain the supplier's trust. Taylor and Plambeck (2007) considered a similar model in which the buyer and supplier have an informal agreement on required capacity. They concluded that the buyer will honor such an agreement because of the future value of cooperation. In both of these models, trust is defined as perceived credibility and is considered to be binary. The trustor either trusts and cooperates, or distrusts and refuses to cooperate.

Our definition of trust differs from previous supply chain models in that: (i) we consider trust on a continuum, with extremes representing complete trust and complete distrust (as proposed in the work of Tardy 1988, Lewicki and Bunker 1995); and (ii) trustworthiness is not only a measure of creditability but also a reflection of competence and social characteristics. Our model also differs from previous work by considering a supply chain with sufficient capacity in which retailer (buyer) and salesperson (representative of the seller) make demand forecasts which may be used by the retailer to make ordering decisions.

A number of papers in behaviorial economics argue that people do not necessarily maximize their own profits when dealing with other people. For example, Bolton and Ockenfels (2000) showed via empirical analysis that people are motivated by both their pecuniary payoff and their relative payoff standing. That is, people care about fairness of the outcomes. Also, Rabin (1993) developed the concept of fairness equilibrium, based on the premise that people like to help those who help them, and hurt those who hurt them. Levine (1998) classified people as being, to various degrees, spiteful or altruistic. Fehr and Schmidt (1999) argued that there are many examples indicating that people are more cooperative than is assumed in the standard self-interest model and there are also contrary pieces of evidence indicating that virtually all people behave as if completely selfish. Fehr and Schmidt (1999) showed that if some people care about equity this puzzling evidence can be resolved and that the economic environment determines whether the fair types or the selfish types dominate equilibrium behavior. This finding bolsters our assumption of the possibility of non-selfish types of salespersons. In a similar vein, the paper by Charness and Rabin (2002) introduced a model in which people care about others' payoff by sacrificing own payoff; specifically they sacrifice for people with low payoffs and they punish unfair players. Additional discussion of 
non-selfish behavior can be found in Ho et al. (2006), which reviewed six behavioral economics models that are useful to marketing. In particular, Cui et al. (2007) incorporated the concept of fairness in a conventional dynamic channel to investigate how fairness may affect channel coordination. They showed that when channel members are concerned about fairness, the manufacturer can use a simple wholesale price contract to achieve maximum channel profit. Inspired by these behaviorial models, we define a utility function for the salesperson that incorporates social preferences.

The research most closely related to our work is Ozer et al. (2011). They investigated the capacity investment problem of a supplier who solicits private forecast information from a manufacturer. To ensure abundant supply, the manufacturer has incentive to inflate her forecast in a costless, non-binding, and nonverifiable type of communication. They conducted a controlled laboratory experiment and determined that, even with a single interaction, the supplier trusts the manufacturer to some extent, which is in contrast with predictions from the analytical game theoretic approach. They also developed a model of trust to incorporate both pecuniary and non-pecuniary incentives and showed that their model fits data from their behavioral experiments. They suggested that the supplier does not use Bayes' rule to update his belief about demand but instead makes use of a linear combination of his own (conditional) prior and what the manufacture reports as her private signal. In our model, we use similar model of trust to explain the behavior of the retailer. However, unlike Ozer et al. (2011), we also propose a trust updating mechanism that is used to model how trust is built up over time.

Our work differs from previous work of information sharing in supply chains in that we have incorporated the concept of social characteristics and trust into the supply chain dynamics. Figure 1 depicts this difference by contrasting a typical model from the literature (e.g., Ebrahim-Khanjari et al. 2011) on the left and the model we study in this article on the right.
In this article, we show that introduction of social characteristics and trust into the supply chain model impacts the influence of a salesperson, as well as the effectiveness of the salesperson compensation scheme.

The remainder of the article is organized as follows. In section 3, we develop our model. In section 4, we study the optimal order recommendation strategy of different types of salespersons. Section 5 presents our numerical experiments; in section 5.2 we study the case in which the retailer has worse forecasting accuracy than the salesperson; and in section 5.3, we consider the case where the retailer has better forecasting accuracy than the salesperson. In these two sections, we examine the impact of the social characteristics of trust, skepticism, and truthfulness on supply chain performance. Finally, we summarize our insights into the role of trust in supply chains and suggest future research directions in section 6 .

\section{Trust Building in Forecast Sharing}

To provide a rigorous framework for examining the role of trust in a supply chain, we use a discretetime model with a manufacturer, a retailer, and a wholesale salesperson, who is hired by the manufacturer to facilitate the ordering process. In each period (a month in the auto industry that motivated this work), the sequence of events is as follows: the retailer and the salesperson independently forecast demand for the period. Next, the salesperson recommends an order quantity to the retailer. The suggestion of the salesperson depends on various factors including her social characteristics and her compensation scheme. After learning the salesperson's recommendation, the retailer places an order quantity based on his own forecast, the salesperson's recommendation, and his trust in the salesperson. Finally, demand is realized, profits are earned, the salesperson is compensated, the retailer updates his trust in the salesperson and the process repeats in the next period. We translate these dynamics into a model below.

Figure 1 Left: A Typical Supply Chain Model with a Salesperson. Right: Supply Chain Model in This Article
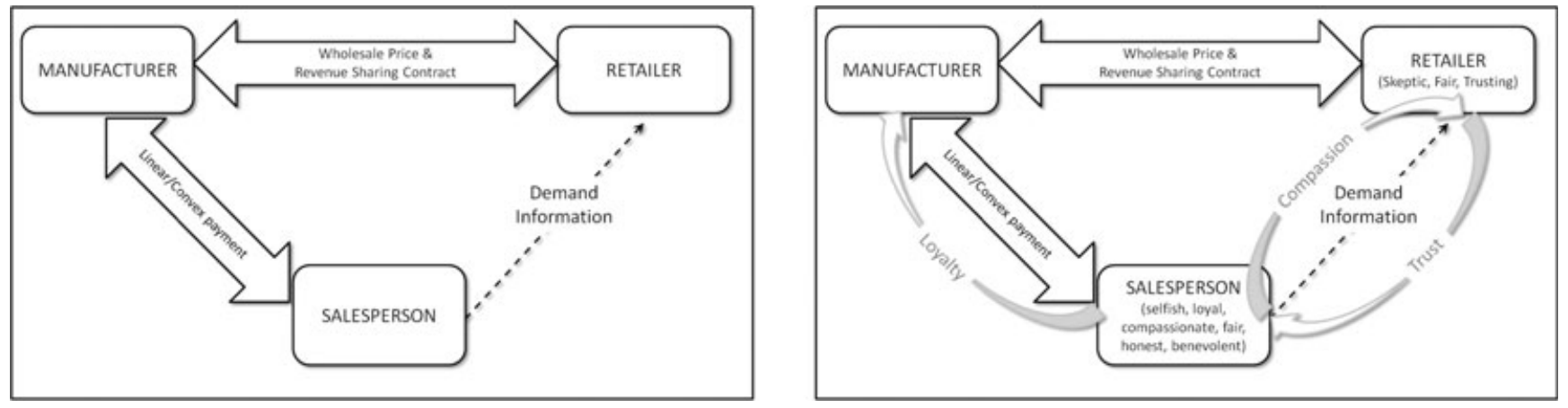


\subsection{Forecasting Model}

We model market demand in a given period as a discrete random variable $D \in\{\underline{d}, \underline{d}+1, \underline{d}+2, \ldots, \bar{d}\}$, where $\underline{d}$ and $\bar{d}$ are integers that denote the lower and upper bounds on market demand, respectively. We denote the cumulative probability distribution of market demand by $G(\cdot)$ and the probability mass function for this distribution by $g(\cdot)$.

As our focus is on the role of trust, we will assume that demand is independent across periods. This eliminates the need for time series forecasting methods. Note that having a time series element in the forecasting process could be allowed within our framework. But in order for the interesting issues of trust to arise, the salesperson and retailer must have access to at least some different information. Hence, for simplicity, we focus only on the outcomes of the forecasting processes of the salesperson and the retailer, rather than the processes themselves. As it does not affect the results, we make the further simplification that demand at any given period is uniformly distributed on $\{\underline{d}, \underline{d}+1, \ldots, \bar{d}\}$.

We assume that the salesperson and the retailer make their forecasts in each period independently. We also assume that the salesperson knows the accuracy of the retailer's demand forecast (i.e., she knows the distribution of the retailer's forecast), but the retailer does not know the accuracy of the salesperson's forecast. We base this assumption on our observation of the interaction between wholesale salespersons and dealers (retailers) in the automotive supply chain. Because of the nature of the salesperson's job, she tracks behavior of the dealer much more closely than the dealer tracks the salesperson's behavior. Moreover, although the dealer has no incentive to hide his true forecast, the salesperson may have incentive to exaggerate her forecast in an attempt to increase the dealer's order quantity. Hence, it is difficult for the dealer to evaluate the salesperson's true forecast accuracy.

Mathematically, we represent the forecast of the retailer at a given period as a discrete random variable $F^{r} \in\{\underline{d}, \underline{d}+1, \ldots, \bar{d}\}$. To model the accuracy of the retailer's forecast, we assume that, given the actual market demand in a period is $D=d$, the cumulative conditional probability distribution of the retailer's forecast is denoted by $G^{r}(\cdot \mid d)$ and is given by a discrete beta distribution with mode $d$ and standard deviation of $\sigma_{r}$. We use the beta distribution because it has a very flexible shape distribution and is also amenable to Bayesian updating. We denote the probability mass function for the conditional distribution that represents retailer's forecasts by $g^{r}(\cdot \mid d)$. Hence, when the retailer's forecast at a given period is $F^{r}=f^{r}$, the retailer can use Bayes' rule to compute the corresponding market demand distribution as follows:

$$
\operatorname{Pr}\left(D=d \mid F^{r}=f^{r}\right)=\frac{g^{r}\left(f^{r} \mid d\right) g(d)}{\sum_{i=0}^{n-1} g^{r}\left(f^{r} \mid \underline{d}+i\right) g(\underline{d}+i)},
$$

where $n=(\bar{d}-\underline{d}+1)$ is the number of discrete values of demand.

Similarly, we model the forecast of the salesperson at any given period as a discrete random variable $F^{s} \in\{\underline{d}, \underline{d}+1, \ldots, \bar{d}\}$. Given the actual demand at any given period is $D=d$, then the cumulative conditional distribution of the salesperson's forecast is denoted by $G^{s}(\cdot \mid d)$ and is given by a discrete beta distribution with mode of $d$ and standard deviation $\sigma_{s}$. The probability mass function of this conditional distribution is given by $g^{s}(\cdot \mid d)$. Hence, when the salesperson's forecast at any given period is $F^{s}=f^{s}$, the salesperson can compute the corresponding market demand distribution as follows:

$$
\operatorname{Pr}\left(D=d \mid F^{s}=f^{s}\right)=\frac{g^{s}\left(f^{s} \mid d\right) g(d)}{\sum_{i=0}^{n-1} g^{s}\left(f^{s} \mid \underline{d}+i\right) g(\underline{d}+i)} .
$$

Note that since $G^{s}(\cdot \mid d)$ and $G^{r}(\cdot \mid d)$ have the same mode, $\sigma_{r}$ and $\sigma_{s}$ represent the accuracy of the retailer's and salesperson's forecasts, respectively. When $\sigma_{s}<\sigma_{r}$ (when $\sigma_{s}>\sigma_{r}$ ), salesperson (retailer) has a more accurate forecast than the retailer (salesperson).

\subsection{Profit Functions}

We assume the wholesale and retail prices (i.e., $p_{w}$ and $p_{r}$ ) are pre-determined and fixed. We also assume that the manufacturer has sufficient production capacity to meet the retailer's order so that manufacturer shortages are not an issue. We assume that any leftover inventory at the retailer level is sold for a unit salvage value (represented by salvage value $h_{r}$ ) at the end of the period; and the retailer is penalized for any unfulfilled demand at a unit shortage cost of $s_{r}$. Hence, the retailer profit at a given period, when he orders $q$ and demand turns out to be $d$, is

$$
\Pi^{r}(q, d)=p_{r} \min \{d, q\}-p_{w} q+h_{r}[q-d]^{+}-s_{r}[d-q]^{+},
$$

where $[x]^{+}=\max \{x, 0\}$. Furthermore, when the retailer's order quantity is $q$, the manufacturer's profit function is given by

$$
\Pi^{m}(q)=\left(p_{w}-c\right) q-\pi^{s}(q),
$$

where $\pi^{s}(q)$ is the payment of the manufacturer to the salesperson and $c$ is the production cost. We consider two different compensation schemes to the salesperson:

1. Simple linear scheme: This compensation scheme is based on a commission rate $(a)$ and a base 
(constant) salary $(b)$. The payment to the salesperson when the retailer orders $q$ is

$$
\pi^{s}(q)=a q+b .
$$

2. Convex compensation scheme: This payment is similar to the linear compensation scheme, except that it also includes a bonus commission rate that applies after the salesperson has reached a target level $\tilde{q}$. Specifically, the payment to the salesperson when the retailer orders $q$ is

$$
\pi^{s}(q)=a_{1} q+a_{2}[q-\tilde{q}]^{+}+b
$$

where $a_{1}$ is the commission rate, for units sold below (or equal to) the target level of $\tilde{q}, a_{2}\left(>a_{1}\right)$ is the bonus commission rate which is paid on items sold above the target level of $\tilde{q}, \tilde{q}$ is the target level, and $b$ is the constant salary.

The retailer's optimal order quantity in a given period when his forecast of demand is $f^{r}$ is $q^{r^{*}}\left(f^{r}\right)$ and is determined by the order quantity that maximizes the retailer's expected profit:

$$
\begin{aligned}
q^{r^{*}}\left(f^{r}\right)= & \arg \max _{q} \mathbb{E}\left[\Pi^{r}(q, d) \mid F^{r}=f^{r}\right] \\
= & \arg \max _{q} \sum_{i=0}^{n-1} \Pi^{r}(q, \underline{d}+i) \\
& \operatorname{Pr}\left(D=\underline{d}+i \mid F^{r}=f^{r}\right),
\end{aligned}
$$

where $\operatorname{Pr}\left(D=d \mid F^{r}=f^{r}\right)$ is given in Equation (1).

For the same scenario, the salesperson has a different optimal order quantity (i.e., which maximizes the retailer's expected profit), because her forecast of demand is $f^{s}$ instead of $f^{r}$, which is

$$
\begin{aligned}
q^{s^{*}}\left(f^{s}\right)= & \arg \max _{q} \mathbb{E}\left[\Pi^{r}(q, d) \mid F^{s}=f^{s}\right] \\
= & \arg \max _{q} \sum_{i=0}^{n-1} \Pi^{r}(q, \underline{d}+i) \\
& \operatorname{Pr}\left(D=\underline{d}+i \mid F^{s}=f^{s}\right),
\end{aligned}
$$

where $\operatorname{Pr}\left(D=d \mid F^{s}=f^{s}\right)$ is given in Equation (2). Note that $q^{s^{*}}$ and $q^{r^{*}}$ depend on $f^{s}$ and $f^{r}$, respectively. Although $q^{s^{*}}$ represents the salesperson's best estimate of the optimal order quantity, she may have incentive to recommend another value to the retailer. For example, the salesperson may be motivated to suggest more than this optimal order quantity to increase her commission-based compensation. Hence, the salesperson's recommended order quantity, which we denote by $Q^{s}$, may not be the same as this optimal order quantity $q^{s^{*}}\left(f^{s}\right)$.

The salesperson recommended order quantity $Q^{s}$ may depend on various factors including the compen- sation scheme of the salesperson and the salesperson's social characteristics. We define the bias (or lie) of the salesperson, $\beta$, as the difference between the recommended order quantity of the salesperson and her corresponding maximizer of the retailer's profit. That is,

$$
\beta=Q^{s}-q^{s^{*}}\left(f^{s}\right) .
$$

\subsection{Salesperson's Preferences}

Some papers have noted that in real world settings, in addition to monetary payoff, other factors may affect the behavior of people in social interactions. For example, Charness and Rabin (2002) argued that people are willing to sacrifice their own payoff to benefit a low payoff player or to punish unfair players. To incorporate such social characteristics in our model, we use a similar approach to that of Charness and Rabin (2002) and assume the utility function of the salesperson when the retailer orders $q$ and demand turns out to be $d$ is

$$
\begin{aligned}
U^{s}(q, d) & =\theta \pi^{s}(q)+(1-\theta) \rho\left[\lambda \Pi^{m}(q)\right. \\
& \left.+(1-\lambda) \Pi^{r}(q, d)\right],
\end{aligned}
$$

where $\pi^{s}, \Pi^{m}$, and $\Pi^{r}$ are the income of the salesperson, the profit of the manufacturer, and the profit of the retailer, respectively; $\theta \in[0,1]$ is the selfishness parameter, which indicates the importance of the salesperson's own payoff relative to the profits of other supply chain's members; $\rho \in[0,1]$ is a scaling factor that makes the profit of the manufacture or retailer comparable to that of the salesperson ${ }^{2}$; and $\lambda \in[0,1]$ is a parameter, which we call the loyalty factor, that indicates how much the salesperson cares about the manufacturer's profit vs. that of the retailer.

The parameters $\theta$ and $\lambda$ characterize the attitude of the salesperson toward the manufacturer and the retailer. The lower the value of $\theta$, the more the salesperson is willing to sacrifice her benefits to gain social relationships. For example, if the manufacturer treats the salesperson fairly then he would expect the salesperson to be loyal and willing to sacrifice small monetary payoffs to increase the manufacturer's profit in large amounts. This behavior corresponds to small $\theta$ and large $\lambda$. By contrast, if the salesperson is treated poorly by the manufacturer, but has a friendly relationship with the retailer, then salesperson may be willing to sacrifice her own payoff (i.e., $\theta$ is small) to benefit the retailer and/or punish the manufacturer (i.e., $\lambda$ is small). Hence, these parameter values and the compensation scheme of the salesperson result in different behaviors from the salesperson and, consequently, different supply chain profits.

To gain insight into the impact of the social preferences of the salesperson on the performance of a 
supply chain, we consider the range of possible behavior implied by Equation (6) by considering the possible combination of $\theta$ and $\lambda$ as follows:

- Selfish self-serving salesperson: This represents a salesperson who only cares about her own payoff. This "classic economics" type of salesperson can be modeled by setting $\theta=1$.

- Loyal self-serving salesperson: This represents a salesperson who has some loyalty to the manufacturer. Therefore, although she cares about her own payoff, she also cares about the manufacturer's profit. This loyal type of salesperson exhibits the reciprocal notion of fairness proposed by Rabin (1993) and can be modeled by setting $\theta<1$ and $\lambda=1$.

- Fair self-serving salesperson: This represents a salesperson who has a close relationship with both the manufacturer and the retailer. Although she cares about her own payoff, she also cares about the profits of both the retailer and the manufacturer. This fair type of salesperson is consistent with the cooperative notion of fairness analyzed by Fehr and Schmidt (1999) and can be modeled by setting $\theta<1$ and $0<\lambda<1$.

- Compassionate self-serving salesperson: This represents a salesperson who has a close relationship with the retailer. Hence, although she cares about her own payoff, she also cares about the retailer's profit. This compassionate type of salesperson matches the altruistic behavior noted by Levine (1998) and can be modeled by setting $\theta<1$ and $\lambda=0$.

As benchmarks, we also consider the following two types of salesperson:

- Honest: This type of salesperson never lies for profit. Therefore, she only reports her forecast without adjustment due to her own utility function or other factors.

- Benevolent salesperson: This type of salesperson only cares about the retailer's payoff. We can model this type of salesperson with $\theta=0$ and $\lambda=0$.

Note that the benevolent salesperson can be conceptualized as a salesperson who is employed by the retailer. Also note that under a commission-based compensation scheme, the utility function of the loyal salesperson is very similar to that of a selfish salesperson. In our results, we find that the loyal, fair, and selfish salespersons have very similar impacts on the supply chain. Therefore, for readability, we have omitted loyal and fair types of salesperson from further consideration.

\subsection{Modeling Trust}

At each period $t$, the retailer is faced with two order quantities, his own optimal order quantity $q_{t}^{r^{*}}$ and salesperson's recommended order quantity $Q_{t}^{s}$. As suggested by Stone (1961) and Clemen and Winkler (1999), we assume that the retailer combines the two order quantities using a simple weighted average:

$$
Q_{t}^{r}=\left(1-w_{t}\right) q_{t}^{r^{*}}+w_{t} Q_{t}^{s},
$$

where $w_{t} \in[0,1]$ is the weight allocated to the salesperson's recommended order quantity in period $t$.

Research has shown that information provided by a trusted party is used more and is considered to have greater value to the trustor (Moorman et al. 1992). Hence, the more the retailer trusts the salesperson, the more weight he puts on her recommendation. Because placing a greater weight on the salesperson's recommended order quantity greatly impacts the retailer's short-term profit, it is an act of trust. Hence, we can view the weight on the salesperson's forecast as a measure of the retailer's trust in the salesperson.

After the retailer purchases order quantity $Q_{t}^{r}$, the actual market demand $d_{t}$ is realized. The retailer compares the relative accuracy of his forecast to that of the salesperson and updates, $w_{t+1}$, his weight on salesperson's recommendation in the next period. Research has shown that individuals update trust in one another based on experience. Mayer et al. (1995) proposed that in organizational relationships, "outcomes of trusting behaviors will lead to updating of prior perceptions of the ability, benevolence and integrity of the trustee." Kramer (1999) suggested that decision makers assess interaction histories to provide a basis for drawing inferences regarding their trustworthiness and for making predictions about the future behavior of others. Hence, whenever the salesperson's forecast is more accurate than the retailer's, we would expect the retailer's perception of the salesperson's ability and integrity to increase. On the other hand, whenever the salesperson's forecast is less accurate than that of the retailer, the retailer may begin to doubt the honesty and/or competence of the salesperson. In our model, this implies that the retailer adjusts his weight on the salesperson's recommendation based on her past forecasting accuracy.

We model the updating process using a simple model in which, $w_{t+1}$, the weight in period $t+1$ is a linear combination of the weight in period $t$ and the relative accuracy of the salesperson's forecast:

$$
w_{t+1}=w_{t}+\delta\left(\left|d_{t}-q_{t}^{r^{*}}\right|-\left|d_{t}-Q_{t}^{s}\right|\right),
$$

where $d_{t}, q_{t}^{r^{*}}$, and $Q_{t}^{s}$ are the realized demand, optimal order quantity of the retailer before considering the 
salesperson's recommendation, and recommended order quantity of the salesperson in period $t$, respectively, and $\delta$ is a sensitivity parameter that reflects the speed with which the retailer gains or loses trust in the salesperson. Note that $\left|d_{t}-q_{t}^{r^{*}}\right|$ represents how far the actual demand at period $t$ was from the order quantity that the retailer was planning to make if he did not take the salesperson's recommendation into account (i.e., if the retailer did not trust the salesperson at all). Similarly, $\left|d_{t}-Q_{t}^{s}\right|$ represents how far the actual demand at period $t$ would have been from order quantity of the retailer, if the retailer completely trusted the salesperson and ordered whatever quantity salesperson suggested. If $\left|d_{t}-q_{t}^{r^{*}}\right|-\left|d_{t}-Q_{t}^{s}\right|>0$ (or $\left.\left|d_{t}-q_{t}^{r^{*}}\right|>\left|d_{t}-Q_{t}^{s}\right|\right)$, then, in period $t$, the retailer could have better matched his order quantity with demand if he had completely trusted the salesperson. In this case, $w_{t+1}$, the retailer's trust in period $t+1$ should increase (compared to that in period $t$ ). On the other hand, $\left|d_{t}-q_{t}^{r^{*}}\right|<\left|d_{t}-Q_{t}^{s}\right|$ implies that in period $t$, the retailer could have better matched his order quantity with demand if he had not trusted the salesperson at all. This results in a lower trust in period $t+1$.

The literature on trust suggests that the rates of gain or loss of trust may not be symmetric (Mcknight and Chervany 1996). Typically, negative experiences cause trust to be lost more quickly than positive experiences cause it to be gained back. To represent this, we model $\delta$ via two separate parameters, one for gains $\delta_{g}$, and one for losses $\delta_{l}$, such that:

$$
\delta= \begin{cases}\delta_{g}, & \text { if }\left|d_{t}-q_{t}^{r^{*}}\right| \geq\left|d_{t}-Q_{t}^{s}\right| \\ \delta_{l}, & \text { if }\left|d_{t}-q_{t}^{r^{*}}\right|<\left|d_{t}-Q_{t}^{s}\right|,\end{cases}
$$

and $\delta_{g}, d_{l} \geq 0$. When $\delta_{l} / \delta_{g}$ is large (and $>1$ ), it is easier to gain the retailer's trust than to lose it. We label a retailer with this behavior as trusting. When $\delta_{l} / \delta_{l}$ is small (and $<1$ ), it is harder to gain the retailer's trust than to lose it. We label a retailer with this behavior as skeptical. Furthermore, $\delta_{l} / \delta_{g}$ is a measure of skepticism of the retailer, which we call the level of skepticism. For modeling purposes, we will assume that the salesperson knows $\delta_{g}$ and $\delta_{l}$. In practice, the salesperson could estimate the rates of trust gain and loss by analyzing the actual order quantities over time.

In addition to the trust updating mechanism, the initial trust level (i.e., initial weight $w_{1}$ ) reflects the ability of the salesperson to influence retailer decisions at the beginning of the relationship. This initial weight can be affected by a variety of factors, including the salesperson's reputation (Ganesan 1994), first impressions from initial interactions (McKnight et al. 1998), and the retailer's emotional state and back- ground (Gachter et al. 2004). To capture the evolution of trust without adding another level of information asymmetry, we assume that the initial weight is known to both parties.

\section{Model Formulation}

To compute the salesperson's optimal policy (i.e., what order quantities to recommend in each period), we make use of dynamic programming. As we assume that excess inventory is sold at a reduced price (a reasonable approximation of what happens in an auto dealership), inventory from previous periods does not carry over. We consider a finite horizon with $T$ periods, where $T$ represents the length of the relationship between the salesperson and the retailer. Later in this article, we study the effects of the length of the relationship on the salesperson's behavior and on supply chain performance. The state space at period $t$ includes the current trust level $w_{t}$ and the salesperson's forecast $f_{t}^{s}$ for the current period demand. We can specify the dynamic program as follows:

- Decision epochs are defined at the beginning of every period right after the salesperson makes her forecast of demand.

- State space $S$ at period $t$ includes states $\left(w_{t}, f_{t}^{s}\right)$, where $f_{t}^{s} \in\{\underline{d}, \underline{d}+1, \ldots, \bar{d}\}$ is the salesperson's demand forecast for period $t$, and $w_{t} \in[0,1]$ is the trust of the retailer in salesperson at period $t$. Note that if the salesperson knows the initial trust level, she can successively learn the trust of the retailer in the next period by observing the realized demand and finalized order quantity of the retailer in the current period.

- Action space $A$ includes all values of possible bias that can be chosen by the salesperson. As market demand is discrete and uniformly distributed on $\{\underline{d}, \underline{d}+1, \ldots, \bar{d}\}$, we know that the bias level $\beta$ has to take values in increments of 1. Moreover, as discussed in section 3.1, since market demand is bounded above and below, we know that $\beta$ is also bounded such that $\beta \in\left\{q^{s^{*}}-\underline{d}, q^{s^{*}}-\underline{d}+1, \ldots, \bar{d}-q^{s^{*}}\right\}$.

We denote the value function at period $t$ for state $\left(w, f^{s}\right)$ by $V_{t}\left(w, f^{s}\right)$ which represents the total optimal expected utility function of the salesperson from period $t$ until the end of the time horizon (period $t=T$ ). Moreover, we define $v\left(w, f^{s}, Q^{s}\right)$ to be the component of the salesperson's total expected utility function that corresponds to the salesperson's current period expected utility when her forecast is $f^{s}$, her suggested order quantity is $Q^{s}$, and the retailer's trust is $w$. Therefore, we have: 


$$
\begin{aligned}
v\left(w, f^{s}, Q^{s}\right)= & \sum_{f^{r}=\underline{d}}^{\bar{d}} \sum_{d=\underline{d}}^{\bar{d}} \operatorname{Pr}\left(D=d \mid F^{s}=f^{s}\right) g^{r}\left(f^{r} \mid d\right) U^{s} \\
& \left((1-w) q^{r^{*}}\left(f^{r}\right)+w Q^{s}, d\right),
\end{aligned}
$$

where $U^{s}(\cdot, \cdot)$ is given in Equation $(6)$, and $q^{r^{*}}(\cdot)$ is given in Equation (3). We write the optimality equation of the salesperson for period $t \in\{1,2, \ldots, T-1\}$ as:

$$
\begin{aligned}
V_{t}\left(w, f^{s}\right)= & \max _{Q_{t}^{s}}\left\{v\left(w, f^{s}, Q_{t}^{s}\right)\right. \\
& +\sum_{d=\underline{d}}^{\bar{d}} \sum_{f^{r}=\underline{d}}^{\bar{d}} \sum_{f=\underline{d}}^{\bar{d}} \operatorname{Pr}\left(D=d \mid F^{s}=f^{s}\right) g^{r}\left(f^{r} \mid d\right) \\
& \left.\times \operatorname{Pr}\left(F^{s}=f\right) V_{t+1}\left(W\left(w, d, f^{r}, f^{s}, Q_{t}^{s}\right), f\right)\right\},
\end{aligned}
$$

where

$$
W\left(w, d, f^{r}, f^{s}, Q_{t}^{s}\right)=w+\delta\left(\left|d-q^{r^{*}}\left(f^{r}\right)\right|-\left|d-Q_{t}^{s}\right|\right),
$$

and $q^{r^{*}}(\cdot)$ is given in Equation (3). Also,

$$
\operatorname{Pr}\left(F^{s}=f\right)=\sum_{d=\underline{d}}^{\bar{d}} g^{s}(f \mid d) g(d) .
$$

We write the optimality equation of the salesperson in the last period (where $t=T$ ) as:

$$
V_{T}\left(w, f^{s}\right)=\max _{Q_{T}^{s}}\left\{v\left(w, f^{s}, Q_{T}^{s}\right)\right\} .
$$

\section{Numerical Study}

As is probably apparent from the above description, analytical study of the above model is prohibitively complicated. Therefore, in this section, we provide a numerical study to gain some insights into the behavior of the salesperson, trust of the retailer in the salesperson, and supply chain performance when salesperson and retailer have different social characteristics and trust plays a role.

\subsection{Design of Experiments}

To gain insight into trust and its effect on supply chain performance, we examined 43,200 sets of parameters in our numerical study using the above dynamic program. For any set of parameters that we consider, we employ backward induction using Equations (7) and (8) to find the optimal strategy of the salesperson, which includes the optimal order quantity to recommend to the retailer $Q_{s}^{t}$ at any period of time $t=1, \ldots, T$ for any possible trajectory of system states. That is, from Equations (7) and (8), we determine how much the salesperson should recommend the retailer to order $\left(Q_{t}^{s}\right)$ at time $t$, given that at time $t$, the forecast of the salesperson about demand is $f_{t}^{s}$ and the retailer's trust to the salesperson is $w_{t}$. Next, we generate streams of independent random numbers for the demand $d_{t}, \forall t=1, \ldots, T$, the retailer's forecast given the generated demand random variable $f_{t}^{r} \mid d_{t}$, and the salesperson's forecast given the generated demand random variable $f_{t}^{s} \mid d_{t}$. These random variables, combined with the optimal strategy of the salesperson, determine the trajectory of the system states. Based on the trajectory of the system, we can obtain the retailer's trust, retailer's profit, and manufacturer's profit. To obtain a confidence interval of $95 \%$, we conducted 2500 simulation replications for each set of parameters. We describe the ranges of parameters considered in the numerical study in the subsections below.

5.1.1. Salesperson's Preferences. The utility function of the salesperson involves the following parameters: selfishness parameter $\theta$, loyalty factor $\lambda$, and scaling factor $\rho$. We consider two different values for the selfishness parameter $\theta \in\{0.5,1\}$. When $\theta=1$, the salesperson basically does not care about others in the supply chain and her objective is to maximize the sum of her own payoffs $\left(\sum_{j=1}^{T} \pi_{j}^{s}\right)$. When $\theta=0.5$, the salesperson is willing to sacrifice her own payoff for others in the supply chain (manufacturer or retailer or both). In this case, when deciding upon her recommended order quantity to the retailer, the salesperson maximizes a weighted sum of her own payoff (with weight of 0.5) and the profits of other parties (with total weight of 0.5 ). How the salesperson divides this weight between the profits of the retailer and manufacturer depend on her loyalty factor $\lambda$. We consider $\lambda \in\{0,0.5,1\}$, where $\lambda=0$ indicates that the salesperson cares about the retailer's profit but not the manufacturer's. This can be the case, for example, if the salesperson has been mistreated by the manufacturer or has close social connections with the retailer. By contrast, $\lambda=1$ corresponds to the case where the salesperson cares about the manufacturer but not the retailer. For example, if the manufacturer has a good working relationship with the salesperson, the salesperson may feel a sense of loyalty to the manufacturer. Finally, $\lambda=0.5$ is the case where the salesperson is fair and considers the welfare of both the manufacturer and the retailer. For the scaling factor $\rho$, we picked a single value that makes supply chain profit roughly equal to the salesperson's compensation under the linear compensation scheme in the case demand is known. Note that the exact value of $\rho$ is not important; 
Table 1 Different Types of Salespersons Studied

\begin{tabular}{lcccccc}
\hline Parameters & Honest & Benevolent & Compassionate & Fair & Loyal & Selfish \\
\hline$\theta$ & - & 0 & 0.5 & 0.5 & 0.5 & 1 \\
$\lambda$ & - & 0 & 0 & 0.5 & 1 & - \\
\hline
\end{tabular}

it is the combination of the values $\rho, \theta$, and $\lambda$ that define different types of salesperson.

In addition to the above cases, as benchmarks, we also considered an honest salesperson (who could be motivated by a large disutility for lying) and a benevolent salesperson whose utility function can be obtained by letting $\theta=0, \lambda=0$.

Although we analyzed all of the above salesperson types, we have removed results for the loyal and fair salespersons from the study, as they are very similar to the results for the selfish salesperson. Table 1 summarizes the types of salespersons that we studied for this article; the white columns represent the types for which we report results.

5.1.2. Salesperson Compensation Scheme. We used two different compensation schemes for the salesperson: (i) a simple linear commission-based compensation scheme with commission rate $a$ and (ii) a convex compensation scheme in which the salesperson is paid at a lower commission rate $a_{1}$, for units below (or equal to) the target level of $\tilde{q}=(\bar{d}-\underline{d}) / 2$, and she is paid a bonus commission rate $a_{2}\left(a_{2}>a_{1}\right)$, for units above the target level of $\tilde{q}=(\bar{d}-\underline{d}) / 2$.

We set $a_{1}$ to be $4 \%$ of the supply chain's profit margin $p_{r}-c$ and $a_{2}$ to be $2 a_{1}$. The reason for choosing these parameters is that we want to make the salesperson's incentives change rapidly around the target level to amplify the difference between the linear and convex compensation scheme. For the linear model, for each set of parameters, we choose a commission rate, $a$, such that on average the manufacturer pays the same percentage of his total profit to the salesperson under both the linear and convex compensation schemes. This makes the two compensation schemes comparable.

5.1.3. Other Parameters. In this section, we present the values for the remaining parameters of the model.

1. Salesperson's forecast accuracy $1 / \sigma_{s}$ : The salesperson's forecast accuracy is characterized by standard deviation $\sigma_{s}$ of her forecast distribution $G^{s}(\cdot \mid d)$. We considered values of the salesperson's normalized standard deviation to be $0.1,0.15$, and 0.25 , where the salesperson's normalized standard deviation is $\sigma_{s} /(\bar{d}-\underline{d})$.

2. Retailer's forecast accuracy $1 / \sigma_{s}$ : The retailer's forecast accuracy is characterized by the stan- dard deviation $\sigma_{r}$ of his forecast distribution $G^{r}(\cdot \mid d)$. We considered values of the retailer's normalized standard deviation to be $0.1,0.15$, and 0.25 , where the retailer's normalized standard deviation is $\sigma_{r} /(\bar{d}-\underline{d})$.

3. Retailer's level of skepticism $\psi$ : Define $\psi=\delta_{l} / \delta_{g}$, this ratio represents the relative ease with which the salesperson loses the retailer's trust as opposed to gaining it. A small ratio represents a trusting retailer, whereas a large ratio represents a skeptical retailer. We considered values $0.25,1$, and 4 .

4. Cost ratio CR: Define $p_{r}-p_{w}+s_{r}$ as the cost of underage and $p_{w}-s_{r}$ as the cost of overage. Cost of underage represents the loss to the retailer due to a unit shortage, whereas cost of overage represents the unit loss to the retailer if he has leftover inventory. In the newsvendor problem, the ratio of these two numbers is critical to obtain the optimal order quantity. We define $C R$ as the ratio of cost of overage over cost of underage (i.e., $C R=\left(p_{r}-p_{w}+s_{r}\right) /\left(p_{w}-\right.$ $\left.s_{r}\right)$ ). We considered three different values (by changing $p_{w}$ ) of $C R=2.2411,1$, and 0.44621 . These values correspond to $z=\Phi^{-1}(C R)=-0.5$, 0 , and 0.5 , in a newsvendor problem with normally distributed demand, when the retailer's optimal order quantity is less than, equal to, or more than average demand respectively. Note that $\Phi(\cdot)$ is the CDF of the standard normal distribution. In the remainder of the article, we use $z=-0.5,0$, and 0.5 to refer to these cases.

5. Initial trust level $w_{1}$ : This measure represents the initial level of trust the retailer puts in the salesperson's recommended order quantity. We considered values $0,0.25,0.5,0.75$, and 1 .

6. Length of the relationship $T$ : This is the total number of periods the salesperson will work with the retailer. We considered values of 3, 6, $12,24,60,120,240$, and 480 . If periods represent months, then this covers a range from 3 months to 40 years.

Note that the retailer revises his trust level $w_{t}$ periods after he observes actual demand. As demand is stochastic, to attain a minimum confidence interval of $95 \%$ on the trust levels $w_{t}$ for $t=1,2, \ldots, T$, we conducted 2500 simulation replications for each case.

In the remainder of this section, we present our findings and discuss their implications for (i) the factors that promote a salesperson to lie; (ii) the resulting level of trust; and (iii) the effect of the salesperson's behavior on trust, on manufacturer's profit, and on retailer's profit compared with those of a supply chain without a salesperson. 
5.1.4. Validating Trust Mechanism. Figure 2 illustrates the trust level of the retailer toward benevolent and selfish salespersons with various forecasting accuracy levels and social characteristics. This shows that, for a given level of forecasting accuracy, a benevolent salesperson who looks out for the retailer's best interest (depicted on the left) is trusted more than a selfish salesperson who only maximizes her own payoff (depicted on the right). This observation confirms that our trust updating mechanism correctly ranks the salesperson's interests and assigns higher trust to the salesperson with better intentions for the retailer. Furthermore, we see that, for example, a benevolent salesperson (depicted on the right) is trusted more if she has a more accurate forecast than the retailer. That is, the larger $\sigma_{s} / \sigma_{r}$, the higher the retailer's trust in the salesperson (especially in the long term).

Finally, we find that, regardless of initial trust level, trust of the retailer converges fairly smoothly over time to a constant level, which depends on the type of salesperson. This is because after some initial periods, the effect of the initial condition diminishes and the retailer learns the capability and intentions of the salesperson. However, at the end of salespersonretailer relationship, trust of the retailer in a selfserving salesperson declines as depicted in Figure 2 (right). This is because, at the end of the relationship, there are no future benefits for the selfish salesperson that motivate her to maintain the trust of the retailer. Consequently, she focuses on her immediate (shortterm) payoff and inflates her recommended order quantity to maximize her payoff. This results in the retailer losing trust in the salesperson. These observations are indications that the proposed trust updating mechanism reelects social realities.

\subsection{Accurate Salesperson}

A wholesale salesperson usually works with multiple retailers. For example, in the automobile industry it is very common that the manufacturer's representative (the wholesale salesperson) sells cars to different retailers within a region. Because she has access to the overall sales forecast for the region, as well as sales by all retailers in that region, the salesperson often has better forecast accuracy than a single retailer who only sees his own market. In this section, we consider such a salesperson whose forecast accuracy is better than the retailer's. We call her an accurate salesperson.

Recall that we have assumed that the retailer does not know whether the salesperson has a more accurate forecast or not. In this situation, if the salesperson communicates her true forecast and the retailer highly trusts the salesperson, then overall supply chain performance will improve. However, unless the salesperson is fully dedicated to improving the profit of the retailer or unless she is honest, she has incentive to inflate her suggested order quantity to induce the retailer to order more, and thus to increase her own payoff. Therefore, the retailer cannot fully trust the salesperson before he knows whether the salesperson has good intentions (i.e., small $\theta$ and $\lambda$ ) and good forecasting accuracy (i.e., $\sigma_{s}$ is smaller than $\sigma_{r}$ ). The amount that the salesperson inflates her suggested order quantity depends on how she is paid, how selfish she is, how skeptical the retailer is, and the length of her relationship with the retailer. In the following section, we look at these different factors and their impacts on the behavior of the salesperson and also on supply chain profit.

5.2.1. Trust of the Retailer. The salesperson's forecasts can affect supply chain profits only if the salesperson can affect the decisions of the retailer, which only occurs when the retailer trusts the salesperson. Thus, it is important to know under what circumstances the salesperson can gain the trust of the retailer. In this section, we seek insight into this issue. Specifically, we investigate the following questions:

Figure 2 Trust of the Retailer in the Salesperson (Averaged Across 2500 Observations) with Different Relative Forecasting Accuracy $\left(\sigma_{s} / \sigma_{r}\right)$ for $T=24, z=-0.5, \psi=1, w_{0}=50 \%$. Left: A Benevolent Salesperson $(\lambda=0, \theta=0)$. Right: A Selfish Salesperson $(\lambda=1)$
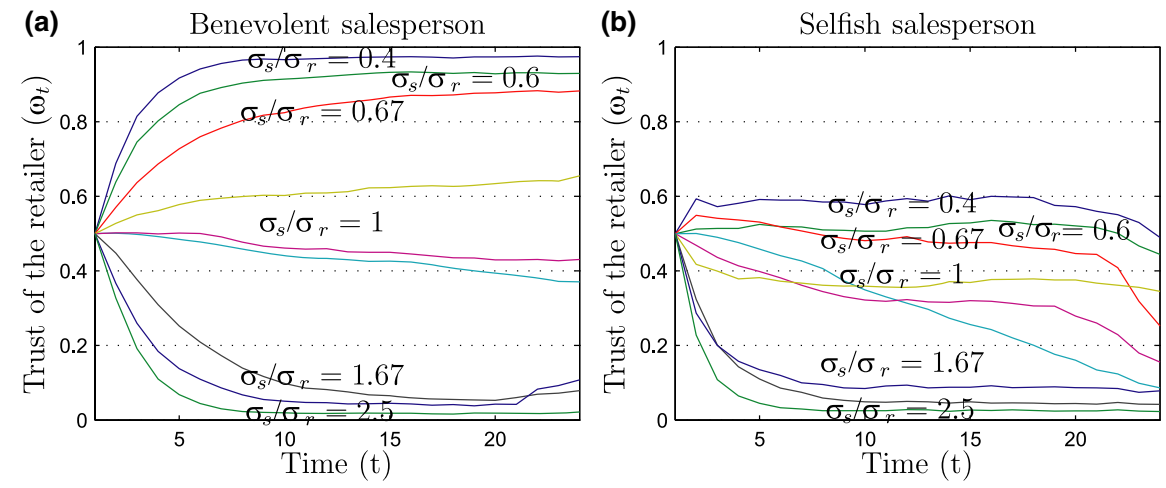
(i) Do the salesperson's social characteristics impact retailer trust (and therefore supply chain performance)? (ii) Can a self-serving salesperson whose incentive is to increase her own payoff gain retailer's trust? If so, to what extent? (iii) How does the salesperson compensation scheme of the salesperson affect retailer trust of the salesperson?

5.2.1.1. Impact of Salesperson's Social Characteristics: When the salesperson's forecast is more accurate than that of the retailer, it is better from a supply chain profit standpoint for the order quantity of the retailer to be based on the salesperson's forecast than on the retailer's forecast. This means that the retailer is better off trusting the salesperson, provided that the salesperson tells the truth. However, because the salesperson's incentive is often not aligned with that of the retailer or the supply chain, the salesperson may not be trustworthy and thus the retailer should not (and does not) completely trust the salesperson. The facts that the salesperson may lie and the retailer does not fully trust the salesperson can reduce supply chain performance. The interesting question is whether retailer trust of salespersons with different intentions is strong enough to allow the salesperson's more accurate forecast to improve supply chain profits. This issue is most critical for a selfish salesperson who only cares about her own payoff, and is thus willing to lie to the retailer (i.e., by inflating her recommended order quantity). Our numerical studies lead to the following:

OBSERVATION 1. When the salesperson's forecasting accuracy is better than that of the retailer $\left(\sigma_{s}<\sigma_{r}\right)$, the retailer highly trusts the salesperson (even a selfish selfserving one). Retailer trust of all types of selfish and compassionate salespersons is considerably larger when the cost of overage is larger than the cost of underage than when the cost of overage is smaller than the cost of underage.
Figure 3 (left) depicts the retailer's trust in different types of salesperson during the retailer-salesperson relationship when the cost of overage is larger than the cost of underage $(z=-0.5)$. In this figure, we can observe that the retailer's trust in different types of self-serving salespersons (compassionate, or selfish salespersons, numbered (3) to (6)) with the two different compensation schemes (linear, solid lines, or convex, shown with dashed lines) is above $75 \%$ in most cases. Furthermore, the retailer's trust in a compassionate self-serving salesperson (numbered (3) with the linear compensation scheme, and (4) with the convex compensation scheme) is above $95 \%$. This implies that with a compassionate salesperson, the retailer relies predominantly on the salesperson's recommendations rather than on his own forecasts.

Similarly, Figure 3 (right) illustrates the retailer's trust in different types of salesperson during the retailer-salesperson relationship when the cost of overage is smaller than the cost of underage $(z=0.5)$. As Figure 3 shows, the retailer's trust level is more than $50 \%$ in most cases. Note that for a given type of the salesperson with a given compensation scheme (e.g., a compassionate salesperson with the convex compensation scheme, numbered (3)), the trust of the retailer is higher when the cost of overage is larger than the cost of underage (Figure 3, left), compared to when the cost of overage is smaller than the cost of underage (Figure 3, right). That is, the salesperson is more influential when the cost of overage is larger than the cost of underage.

The reason that the retailer has high trust in the salesperson (even a selfish accurate salesperson) is that the forecast accuracy of the salesperson is better than that of the retailer. Thus, the salesperson, by recommending a more accurate order size, can improve trust, if she wants to. Although a selfish self-serving salesperson wishes to inflate her recommended order quantity as much as possible, she needs to retain the

Figure 3 Trust of the Retailer in an Accurate Salesperson (Averaged Across 2500 Observations) for $T=24, \psi=1$, and $w_{0}=50 \%$. Left: Cost of Overage Is Larger than Cost of Underage $(z=-0.5)$. Right: Cost of Overage Is Smaller than Cost of Underage $(z=0.5)$. Solid Line: Linear Compensation Scheme. Dashed Line: Convex Compensation Scheme. (1) Honest Salesperson; (2) Benevolent Salesperson; (3) Compassionate Self-Serving Salesperson $(\theta=0.5$, and $\lambda=0)$; (4) Selfish Self-Serving Salesperson $(\theta=1)$

(a) Cost of overage is larger than cost of underage

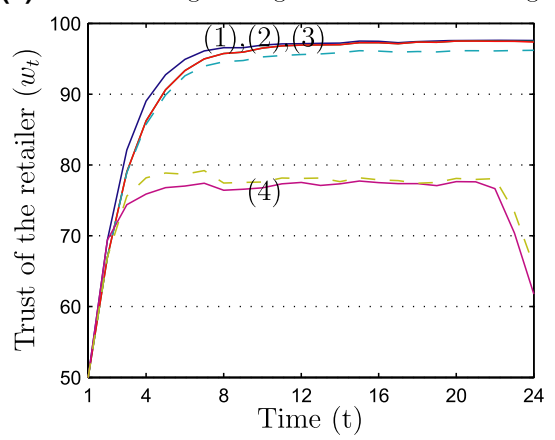

(b) Cost of overage is smaller than cost of underage

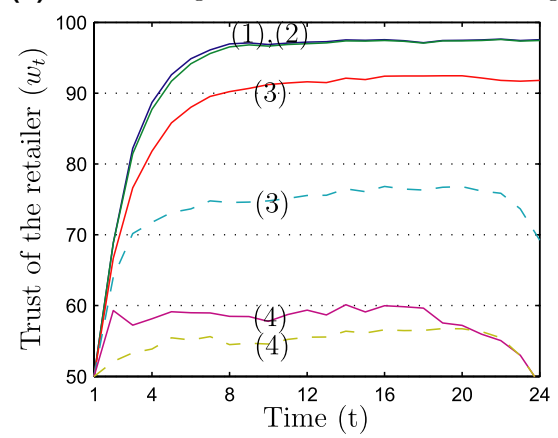


trust of the retailer so that the retailer will consider her input. Consequently, the salesperson does not inflate her recommendation too much, resulting in recommendations that benefit the retailer.

To understand why the retailer trusts the salesperson more when the cost of overage is larger than the cost of underage, consider an extreme case where the cost of overage is much larger than the cost of underage. In this case, the optimal order quantity of the salesperson is smaller than her forecasted demand. Hence, if she inflates her recommendation from her optimal order quantity, her recommendation becomes closer to her forecast of demand, and thus it becomes less likely that she loses trust of the retailer. However, when the cost of overage is much smaller than the cost of underage, the optimal order quantity of the salesperson is larger than her forecasted demand. Hence, if she inflates her recommendation from her optimal order quantity, her recommendation deviates even further from her forecast of demand, and thus it becomes more likely that she will lose trust of the retailer. Thus, it is harder to maintain trust of the retailer when the cost of overage is smaller than the cost of underage as confirmed by Figure 3.

Finally, as we noted earlier, the trust of the retailer in the self-serving salesperson declines in the last few periods, because there is no future relationship and hence the salesperson does not need to maintain the trust of the retailer. Thus, in the last few periods, she exploits whatever trust level she has accumulated up to that point.

5.2.1.2. Impact of Salesperson's Compensation: Incentives of a self-serving salesperson are influenced by both her social characteristics (compassionate, or selfish), which cannot be changed easily, and her compensation scheme (e.g., linear or convex compensation scheme), which is controlled by the manufacturer. Previously, we studied the effects of the salesperson's attitudes on the retailer's trust. Here, we examine the effects of compensation scheme on the behavior of the salesperson and thereby retailer trust in the salesperson. Based on our numerical studies, we have:

OBSERVATION 2. When the salesperson's forecasting accuracy is better than the retailer's $\left(\sigma_{s}<\sigma_{r}\right)$, the type of contract (linear or convex compensation scheme) does not have a significant impact on the behavior (bias) of the salesperson and trust of the retailer, except when the salesperson is a compassionate self-serving salesperson. A convex compensation scheme makes a compassionate selfserving salesperson lie more about order quantity. When the cost of overage is smaller than the cost of underage, the salesperson is trusted less under the convex compensation scheme than under the linear compensation scheme.
In Figure 3 (right), we observe that trust in a compassionate self-serving salesperson with the linear compensation scheme (solid line numbered (3)) is considerably larger than trust in the same type of salesperson with the convex compensation scheme (dashed line numbered (3)). However, the compensation scheme does not affect the retailer's trust of other types of salespersons (e.g., compare a selfish salesperson with the linear compensation scheme (solid line numbered (4)) and with the convex compensation scheme (dashed line numbered (4)).

The intuition behind this observation is that under a convex compensation scheme, the salesperson has additional incentive to inflate her recommended order quantity from her optimal order quantity when the order quantity of the retailer is close to the target level of her compensation. This factor becomes important with a compassionate salesperson, because a compassionate salesperson, unlike other types of selfish salesperson, has conflicting objectives. On one hand, she wants to increase her own payoff (which requires inflating her recommended order quantity), and on the other hand, she does not want to let the retailer lose profit (which means that she must not inflate her recommended order quantity). When the compensation scheme of the salesperson is convex and the optimal order quantity of the salesperson is close to the target level of her compensation, the rate at which the salesperson's payoff increases, suddenly increases if she can convince the retailer to order more than the target level of her compensation scheme, whereas the rate at which the profit of the retailer decreases does not make a sudden change. Hence, the convex compensation scheme of the compassionate salesperson has a large impact on her recommendations. However, selfish salespersons always try their best to increase order quantity of the retailer, so giving them additional incentives to increase their recommendations does not make much difference. Note that, as discussed earlier, when the cost of overage is larger than the cost of underage, the optimal order quantity of the salesperson is smaller than her forecasted demand. Hence, if she inflates her recommendation from her optimal order quantity, her recommendation becomes closer to her forecasted demand, and thus it becomes less likely that she will lose trust of the retailer.

5.2.2. Profits of the Supply Chain. In this section, we study the effects of different factors, such as skepticism, length of relationship, type of salesperson, and compensation scheme of the salesperson, on profits of the retailer, the manufacturer, and total supply chain.

5.2.2.1. Impact of Retailer's Skepticism and Salesperson's Social Characteristics: First, we study the effect of the 
retailer's level of skepticism and the salesperson's attitudes (i.e., types) on the profits of the various supply chain parties. We would like to know: (i) whether the retailer's skepticism has any effect on the effectiveness of a salesperson; (ii) what type of salesperson is beneficial to both the retailer and the manufacturer; and (iii) whether a benevolent salesperson who only has the retailer's profit in mind also benefits the manufacturer. In this regard, we observe the following:

ObSERVATION 3. When the salesperson's forecasting accuracy is better than that of the retailer $\left(\sigma_{s}<\sigma_{r}\right)$,

1. If the cost of overage is larger than the cost of underage, a compassionate or a selfish salesperson is beneficial to both parties only if the retailer is skeptical ( $\psi$ is large). When the retailer is trusting ( $\psi$ is small), only the manufacturer gains from a compassionate or a selfish salesperson. However, a benevolent or honest salesperson is beneficial to both the manufacturer and the retailer (and thus the total supply chain), regardless of the retailer's skepticism.

2. If the cost of overage is smaller than the cost of underage and the length of salesperson-retailer is long enough, a selfish salesperson does not have a significant impact on the profit of the supply chain. However, a compassionate, a benevolent, or honest salesperson increases the profit of the retailer and decreases the profit of the manufacturer.

From this observation, we can conclude that when the length of relationship between the salesperson and the retailer is long, regardless of the type of salesperson and compensation scheme (linear or convex), the manufacturer benefits from hiring the salesperson only if the cost of overage is not much smaller than the cost of underage.

Table 2 shows how the profit of the retailer (top) and the manufacturer (bottom) changes as the retailer becomes more skeptical when the salesperson is benevolent (left) or selfish self-serving (right). In this table, we observe that the benevolent salesperson has a positive effect on profit of both the retailer (top) and the manufacturer (bottom) when the cost of overage is larger than the cost of underage. However, with the same cost structure, the selfish self-serving salesperson (right) always has a positive effect on the profit of the manufacturer but has a negative effect on the profit of the retailer when the retailer is trusting ( $\psi$ is small). Interestingly, we observe that when the retailer becomes more skeptical $(\psi=4)$, the selfish salesperson (depicted on the right) becomes beneficial to the retailer as opposed to when the retailer is less skeptical $(\psi=0.25$ or 1$)$, in which case the selfish salesperson has a negative effect on the retailer's profit.
Table 2 Percent Increase in Profits of the Retailer and the Manufacturer When a Benevolent or a Self-Serving Salesperson Is Hired with a Linear Compensation Scheme When $\sigma_{s}=0.1<\sigma_{r}=0.25$. a,c, Benevolent Salesperson; b,d, Selfish Self-Serving Salesperson; a,b, Increase in Retailer Profit; c,d, Increase in Manufacturer Profit

\begin{tabular}{lrcr}
\hline & \multicolumn{3}{c}{ Critical ratio $(z)$} \\
\cline { 2 - 4 } Level of & \multicolumn{3}{c}{0.5} \\
\hline skepticism $(\psi)$ & -0.5 & 0 & $2.66 \%$ \\
4 & & & $0.97 \%$ \\
1 & $9.04 \%$ & $5.47 \%$ & $2.87 \%$ \\
0.25 & $9.72 \%$ & $5.74 \%$ & $3.00 \%$ \\
(b) & $10.14 \%$ & & \\
4 & & $1.49 \%$ & $0.10 \%$ \\
1 & $1.42 \%$ & $-0.53 \%$ & $-0.23 \%$ \\
0.25 & $-7.05 \%$ & $-3.83 \%$ & $-0.87 \%$ \\
(c) & $-18.34 \%$ & & \\
4 & & $-1.19 \%$ & $-6.33 \%$ \\
1 & $3.86 \%$ & $-1.22 \%$ & $-6.74 \%$ \\
0.25 & $4.27 \%$ & $-1.23 \%$ & $-6.97 \%$ \\
(d) & $4.50 \%$ & & \\
4 & & $1.42 \%$ & $-1.28 \%$ \\
1 & $5.81 \%$ & $3.62 \%$ & $0.10 \%$ \\
0.25 & $8.53 \%$ & $6.53 \%$ & $1.68 \%$ \\
\hline
\end{tabular}

To explain why when the cost of overage is larger than the cost of underage, both the retailer and the manufacturer benefit from a benevolent or honest salesperson, consider the extreme case where $z$ is a very small negative number (e.g., $z<-3$ ). Note that, when the cost of overage is sufficiently larger than the cost of underage, the optimal order quantity of the retailer leads to an understock (i.e., less than his forecasted demand). However, as the salesperson's forecasts are more accurate, her optimal order quantity is to understock less than the retailer. In other words, the optimal order quantity of the salesperson would be, in expectation, greater than that of the retailer. In this case, both a benevolent salesperson (who cares for the retailer) and an honest salesperson (who never lies) recommend an order quantity close to her optimal order quantity (which is, in expectation, larger than what the retailer was thinking to order). This means that both the manufacturer (because of larger order quantities) and the retailer (because of better order quantities) benefit from either a benevolent or an honest salesperson.

Next, we argue that skepticism of the retailer can be beneficial to him. Although (expected value of) the order quantity the retailer has in mind is too small, self-serving salesperson has strong incentive to lie and inflate her recommendation more than would be beneficial to the retailer. If the retailer is too trusting, a self-serving salesperson can easily inflate her recommendation without fear of losing trust of the retailer. By contrast, if the retailer is skeptical, it becomes hard for the salesperson to gain trust of the retailer once 
she loses it. Therefore, the salesperson is discouraged from inflating her order recommendations too much, and thus the retailer can also benefit.

Finally, we explain why, when the cost of overage is sufficiently smaller than the cost of underage, the benevolent or honest salesperson only can be beneficial to the retailer and the self-serving salesperson cannot have much impact on the supply chain. To explain this, consider the extreme case when the cost of overage is significantly smaller than the cost underage (e.g., $z>3$ ). In this case, similar to the above argument, we can argue that the optimal order quantity of the retailer is to overstock (stock more than his forecasted demand). However, as the salesperson's forecasts are more accurate, the optimal order quantity of the salesperson is to overstock less than the retailer. In other words, the optimal order quantity of the salesperson is, in expectation, smaller than that obtained by the retailer. In this case, the benevolent salesperson (who cares for the retailer) and the honest salesperson (who never lies) will recommend an order quantity close to what they think is optimal (which is in expectation smaller than what the retailer has in mind). This means that the manufacturer does not benefit (because of smaller order quantities), whereas the retailer (because of more accurate order quantities) benefits from a benevolent or an honest salesperson.

With respect to total supply profit (i.e., the combined profit of the retailer and the manufacturer), we studied tables similar to Table 2 which, for the sake of space, we have not included here. We observed that when the cost of overage is significantly larger than the cost of underage, the salesperson improves total supply chain profit, regardless of the type of salesperson. However, when the cost of overage is significantly smaller than the cost of underage, total supply chain profit may or may not benefit from the salesperson. If the salesperson's incentives are completely aligned with increasing the retailer's profit or the manufacturer's profit (e.g., the benevolent salesperson or the loyal salesperson), then the total supply chain does not benefit from the salesperson as much as it does with a compassionate salesperson. However, when the salesperson's incentives are such that she emphasizes profits of both the retailer and the manufacturer (e.g., the compassionate salesperson), the incentives of the salesperson are closely aligned with total supply chain profit, and thus the supply chain benefits from the salesperson. Note that even a fair self-serving salesperson, who we defined to be caring for the supply chain, is not as good for the supply chain as a compassionate salesperson, who we defined to be a salesperson who equally cares about her own payoff and the retailer's profit. This is because the fair salesperson's compensation is already such that she heavily favors the manufac- turer's profit and by not emphasizing the retailer's profit as much as a compassionate salesperson does, the fair salesperson's incentive is less aligned with the total supply chain profit than that of a compassionate salesperson.

The above observation suggests that the information of a wholesale salesperson is best utilized, and improves supply chain profit most, when the cost structure is such that the retailer thinks of ordering less than her forecasted demand. In this case, an accurate wholesale salesperson encourages the retailer to order an amount that is larger (on average) and closer to what she thinks is optimal, which benefits both the retailer and the manufacturer. Furthermore, the retailer also highly trusts the salesperson, which may yield benefits in other aspects of the business relationship (e.g., encouraging the retailer to make use of the salesperson's advice on sales promotions, product displays, or other matters).

Next, we study how the manufacturer's and the retailer's profits change if a selfish salesperson is replaced with an honest, compassionate, or benevolent salesperson and the retailer's level of skepticism increases. We provide tables that quantify this change.

OBSERVATION 4. When the cost of overage is larger than cost of underage, the retailer's profit highly depends on type of salesperson. With a benevolent type of salesperson, the retailer achieves the highest profit compared to other types of salespersons.

Table 3 demonstrates the percentage increase in the retailer's profit for a given type of salesperson, compensation scheme of the salesperson, and skepticism of the retailer when compared to a supply chain with a selfish salesperson and a trusting retailer (with level of skepticism of 0.25). For example, a retailer with level of skepticism of 1 in a supply chain with a compassionate salesperson who is paid according to a convex compensation scheme would gain $12.54 \%$ more than a retailer with level of skepticism of 0.25 in a supply chain with a selfish salesperson who is paid according to a linear compensation scheme.

When the cost of overage is smaller than cost of underage, the retailer's profit highly depends on the type of salesperson. This is because in that case, different types of salespersons have opposite objectives. Specifically, when the cost of overage is smaller than cost of underage, as discussed before, a benevolent salesperson whose objective is to increase the profit of the retailer recommends, on average, an order quantity smaller than what the retailer would have ordered before getting the salesperson's recommendation. This behavior of the benevolent salesperson decreases the average profit of the manufacturer and is completely opposite to what a selfish salesperson 
Table 3 Percent Increase in the Retailer's Profit When Selfish Salesperson with Linear Compensation Scheme Is Replaced with Other Types of the Salesperson (as Indicated) and the Retailer Becomes More Skeptical (from Level of Skepticism of 0.25 to 1 or 4 ) When $\sigma_{s}=0.1<\sigma_{r}=0.25$. The cost of overage is (a) larger than cost of underage $(z=-0.5)$ and (b) smaller than cost of underage $(z=0.5)$

\begin{tabular}{|c|c|c|c|c|c|c|}
\hline \multirow[b]{2}{*}{ Level of skepticism $(\psi)$} & \multirow[b]{2}{*}{ Honest } & \multirow[b]{2}{*}{ Benevolent } & \multicolumn{2}{|c|}{ Compassionate } & \multicolumn{2}{|c|}{ Selfish } \\
\hline & & & Linear & Convex & Linear & Convex \\
\hline \multicolumn{7}{|l|}{ (a) } \\
\hline 0.25 & $14.48 \%$ & $14.51 \%$ & $14.50 \%$ & $11.70 \%$ & $0.00 \%$ & $0.55 \%$ \\
\hline 1 & $14.25 \%$ & $14.30 \%$ & $14.28 \%$ & $12.54 \%$ & $5.79 \%$ & $6.04 \%$ \\
\hline 4 & $13.92 \%$ & $13.96 \%$ & $13.95 \%$ & $13.54 \%$ & $10.01 \%$ & $10.30 \%$ \\
\hline \multicolumn{7}{|l|}{ (b) } \\
\hline 0.25 & $1.92 \%$ & $1.94 \%$ & $1.22 \%$ & $0.08 \%$ & $0.00 \%$ & $0.01 \%$ \\
\hline 1 & $1.86 \%$ & $1.88 \%$ & $1.33 \%$ & $0.58 \%$ & $0.31 \%$ & $0.33 \%$ \\
\hline 4 & $1.75 \%$ & $1.77 \%$ & $1.37 \%$ & $1.08 \%$ & $0.49 \%$ & $0.49 \%$ \\
\hline
\end{tabular}

want to do. Therefore, the retailer's profit highly depends on the type of salesperson. On the other hand, when the cost of overage is smaller than the cost of underage, all types of salespersons would like, on average, to increase the order quantity of the retailer to increase the profit of the retailer and manufacturer together. Therefore, when the cost of overage is smaller than the cost of underage, the retailer's profit does not depend much on the type of salesperson.

OBSERVATION 5. With a selfish salesperson who is paid according to a linear compensation scheme and a retailer who is trusting, the manufacturer achieves the highest profit compared to other types of salesperson and other types of retailer.

Table 4 demonstrates how the profit of the manufacturer changes if the selfish salesperson with linear compensation scheme is replaced with other types of salesperson (and/or with different compensation schemes) and the level of skepticism of the retailer increases. For example, if a selfish salesperson is replaced with a compassionate salesperson and the retailer becomes more skeptical (such that the level of skepticism increased from 0.25 to 4 ), the manufacturer can lose as much as $4.14 \%$ percent of profit.
5.2.2.2. Length of Relationship: In this section, we study the effect of the length of relationship on profits of the parties of the supply chain. We are interested in how the length of the retailer-salesperson relationship affects the retailer's profit and the manufacturer's decision to hire a salesperson. Our experiments lead to the following:

OBSERVATION 6. When the salesperson's forecasting accuracy is better than that of the retailer $\left(\sigma_{s}<\sigma_{r}\right)$, independent of cost structure, type of salesperson, and compensation scheme of the salesperson (linear or convex), the retailer and supply chain always benefit from longer relationships (large $T$ ).

Note that as the length of relationship increases, retaining trust of the retailer becomes more important to the salesperson because when the length of relationship is longer, the salesperson can potentially influence more decisions of the retailer toward her own objective (whether it is increasing order quantity of the retailer or it is increasing profit of the retailer). Hence, the salesperson has incentive to suggest a less biased order quantity to maintain retailer trust. Consequently, the retailer and the supply chain gain more from the salesperson's input when the relationship is long.

Table 4 Percent Increase in the Manufacturer's Profit When Selfish Salesperson with Linear Compensation Scheme Is Replaced with Other Types of the Salesperson (as Indicated) and the Retailer Becomes More Skeptical (from Level of Skepticism of 0.25 to 1 or 4 ) When $\sigma_{s}=0.1<\sigma_{r}=0.25$. The cost of overage is (a) larger than cost of underage $(z=-0.5)$ and (b) smaller than cost of underage $(z=0.5)$.

\begin{tabular}{|c|c|c|c|c|c|c|}
\hline \multirow[b]{2}{*}{ Level of skepticism $(\psi)$} & \multirow[b]{2}{*}{ Honest } & \multirow[b]{2}{*}{ Benevolent } & \multicolumn{2}{|c|}{ Compassionate } & \multicolumn{2}{|c|}{ Selfish } \\
\hline & & & Linear & Convex & Linear & Convex \\
\hline \multicolumn{7}{|l|}{ (a) } \\
\hline 0.25 & $-3.88 \%$ & $-3.85 \%$ & $-3.82 \%$ & $-2.78 \%$ & $0.00 \%$ & $-0.08 \%$ \\
\hline 1 & $-4.02 \%$ & $-3.96 \%$ & $-3.94 \%$ & $-3.29 \%$ & $-1.76 \%$ & $-1.89 \%$ \\
\hline 4 & $-4.22 \%$ & $-4.17 \%$ & $-4.14 \%$ & $-3.99 \%$ & $-3.16 \%$ & $-3.22 \%$ \\
\hline \multicolumn{7}{|l|}{ (b) } \\
\hline 0.25 & $-4.28 \%$ & $-4.33 \%$ & $-1.94 \%$ & $-0.05 \%$ & $0.00 \%$ & $-0.00 \%$ \\
\hline 1 & $-4.15 \%$ & $-4.21 \%$ & $-2.21 \%$ & $-1.02 \%$ & $-0.78 \%$ & $-0.80 \%$ \\
\hline 4 & $-3.94 \%$ & $-4.01 \%$ & $-2.47 \%$ & $-2.09 \%$ & $-1.48 \%$ & $-1.48 \%$ \\
\hline
\end{tabular}


5.2.2.3. Salesperson's Compensation Scheme: Finally, we investigate the effect of the compensation scheme of the salesperson on the manufacturer's profit. Specifically, we are interested in how the manufacturer should pay (linear or convex compensation scheme) different types of salespersons. Under the traditional assumption that the salesperson's incentive only depends on monetary payoffs, it is easy to show that the linear compensation scheme is better than the convex compensation scheme (as defined in this article). However, when social characteristics (types) of the salesperson also affect the incentive of the salesperson, this is no longer the case. In particular, we observe the following:

OBSERVATION 7. The compensation scheme of the salesperson, linear or convex, does not have a large effect on manufacturer (and retailer) profit unless the salesperson is a compassionate self-serving salesperson. In that case, the manufacturer is better off (and the retailer and supply chain are worse off), if the manufacturer pays the salesperson according to a convex compensation scheme rather than a linear one, especially when the retailer is trusting ( $\psi$ is small).

As discussed in section 5.2.1, with a convex compensation scheme, the salesperson has additional incentive to inflate her order quantity when the order quantity of the retailer is close to the target level of her compensation. With a compassionate salesperson, who also cares for the profit of the retailer along with her own payoff, it becomes crucial to the manufacturer that the salesperson place less emphasis on retailer profit, especially when the retailer is thinking of ordering more than his forecast of demand. When the compensation scheme of the salesperson is convex and the optimal order quantity of the salesperson is close to the target level, the salesperson can increase her own payoff rapidly without decreasing the retailer's profit too much by inflating her optimal order quantity a little bit. This causes the manufacturer to benefit more from the salesperson. Other types of salesperson already have large incentive to inflate their order quantity and thus changing the compensation scheme does not make them perform better for the manufacturer. When the retailer is trusting, the salesperson can easily gain the trust of the retailer and thus inflation of her suggested order quantity has a less adverse effect on her future payoffs, and thus she can inflate her recommendations more easily than when the retailer is skeptical.

The above discussion suggests that the salesperson lies more under a convex compensation scheme than under a linear one. Therefore, the supply chain with a convex compensation scheme benefits less from an accurate salesperson forecast. This implies that the supply chain as a whole is worse off if the salesperson is paid with a convex compensation scheme than with a linear one.

\subsection{Inaccurate Salesperson}

A wholesale salesperson performs various tasks, such as market demand promotion, introducing new products to the retailer, administrative work related to advertising, and many others. In cases where the salesperson's tasks are more focused on issues other than forecasting demand, the salesperson's forecast accuracy may be less than the retailer's. In the previous section, we restricted ourselves to the case where the forecasting accuracy of the salesperson is better than that of the retailer, which implies that relying on the salesperson's forecast can potentially improve the profit of the supply chain. In this section, we study the case where the salesperson's forecasting accuracy is not as good as the retailer's. We are interested in whether such a salesperson can improve the profit of the manufacturer. To find out, we repeated our entire numerical study for this case and we found that:

OBSERVATION 8. When the forecasting accuracy of the retailer is better than the salesperson's $\left(\sigma_{s}>\sigma_{r}\right)$ :

- No type of salesperson can maintain a high level of retailer trust.

- In the long run, different types of salesperson (with linear or convex compensation schemes) have similar effects on the supply chain parties. While the effect on retailer profit is not substantial, there is a negative effect on the manufacturer profit. Consequently, the manufacturer is better off not to hire a salesperson.

When the retailer has a more accurate forecast than that of the salesperson, after some interactions, the retailer will learn that the salesperson is not worthy of trust (even if the salesperson has good intentions). This implies that the salesperson cannot affect the decisions of the retailer in the long run, and therefore she cannot change the profit of the supply chain. However, because the manufacturer must pay the salesperson regardless of her influence, the manufacturer is better off not hiring the salesperson in the first place.

We would like to emphasize that, in practice, apart from influencing the retailer's decisions, a wholesale salesperson performs other tasks, including promoting consumer demand of a manufacturer's products, building long-term relationships with the retailers, and collecting market-demand information. The above observation specifies that when the salesperson does not have more accurate market demand information than the retailer, she cannot benefit the 
retailer by influencing the retailer's ordering decisions. However, she may still generate profit for the manufacturer by influencing the supply chain in other ways.

It may be interesting to look at the behavior of the salesperson when the retailer does not find her trustworthy. In this regard, we observe that

OBSERVATION 9. The salesperson, even a benevolent one, lies more when the retailer's forecast is more accurate than her own. When the cost of overage is smaller than the cost of underage, the salesperson, on average, recommends an order quantity that is less than what she thinks is optimal for the retailer (even a self-serving salesperson).

To explain why the benevolent salesperson lies on average, we follow the behavior of the salesperson over time under different conditions, which leads us to observe:

- When the trust of the retailer in the salesperson is large, the benevolent salesperson does not lie and suggests her optimal order quantity to the retailer.

- When the trust of the retailer is very small (almost zero), the salesperson lies and recommends an order quantity close to her forecast of demand (which is not her optimal order quantity).

- When the trust of the retailer is at an intermediate level, the benevolent salesperson lies and recommends an order quantity as far from her forecast of demand as possible.

Note that at the end of the salesperson-retailer relationship, the benevolent salesperson never lies, as she is not concerned with maintaining or gaining trust of the retailer and thus she suggests whatever she thinks is best for the retailer.

The intuition behind the first observed behavior is that whenever the trust of the retailer is large, the retailer relies mostly on the recommendation of the salesperson. This means that it is mostly the salesperson who should decide how much the retailer should order. Therefore, as the benevolent salesperson is concerned about the retailer's interest, her suggestion should be her optimal order quantity, to maximize the retailer's profit, which is the same as the benevolent salesperson's utility function. However, as the forecast accuracy of the salesperson is much worse than that of the retailer, she cannot be as good as the retailer and very soon the retailer loses trust in the salesperson. Hence, we very rarely observe the first behavior.

To explain the second observed behavior, we note that when retailer trust of the salesperson is small, the salesperson gives her best forecast of demand (which is not her optimal order quantity) with the intent of influencing the order quantity of the retailer a little toward what she thinks demand would be. When the cost of overage is sufficiently smaller than the cost of underage, the optimal order quantity of the salesperson includes some safety stock on top of her forecasted demand. Hence, to suggest her best forecast of demand, the salesperson lies and deflates her optimal order quantity. Conversely, when the cost of overage is sufficiently larger than the cost of underage, she inflates her optimal order quantity.

Finally, to understand the third observed behavior, we note that when the retailer's trust is at an intermediate level, the salesperson lies as much as possible so as to signal the retailer to reduce his reliance on the salesperson's forecast in future periods. That is, the salesperson tries to keep retailer trust level positive but small so that she can influence the order quantity of the retailer a little toward what she thinks the actual demand is.

As mentioned above, as the salesperson's forecast is worse than that of the retailer, she cannot maintain high trust of the retailer. Hence, in most cases we observe the second and the third behavior above. In other words, the benevolent salesperson lies most of the time.

\section{Summary}

While it is widely acknowledged in industry that relational factors play an important role in supply chain performance and coordination, operations management research has generally relegated such issues to the category of "intangibles." At best, the development of trust has been modeled as something that evolves in a "black box" and is therefore not directly addressed. Furthermore, in most supply chain papers, the issue of social characteristics of the various parties is ignored. In this study, we have made a preliminary step toward modeling trust and social characteristics as dynamic and quantifiable components of supply chain decisions. This has allowed us to examine the evolution of trust and its impact on the supply chain members' behavior.

We find that even a benevolent salesperson who focuses on retailer's profit does not necessarily tell the truth. In fact, she often tells white lies to increase retailer profit, especially when her forecasting accuracy is inferior to that of the retailer. By contrast, a self-serving salesperson manipulates the retailer to order more stock by lying. Particularly when her forecasting skill is superior, she is successful in inducing the retailer to order more while maintaining some trust of the retailer. We also find that when the forecasting accuracy of the salesperson is worse than that of the retailer and the cost structure is such that the 
cost of overage is smaller than the cost of underage, a self-serving salesperson suggests less than what she thinks is optimal for the retailer to order. In addition to social characteristics, salesperson behavior is influenced by the compensation scheme. We find that if the salesperson is concerned about profit loss of the retailer, a convex compensation scheme is better than a linear compensation scheme from the perspective of the manufacturer. This is in stark contrast with the optimality of a linear compensation scheme for the scenario without social characteristics. We also observe that both the manufacturer and retailer can benefit from hiring a salesperson with good forecasting accuracy, particularly when the cost of underage is smaller than the cost of overage.

In general, regardless of how manipulative a selfserving salesperson is, time (i.e., duration of the relationship) has the power to reveal her competence (i.e., actual forecast ability). In a long-term relationship, a self-serving salesperson is more cautious about the trade-off of immediate gain (current order quantity) and value of future cooperation (which affects future orders). As a result, the retailer always gains from longer relationships. Benevolent actions induce greater trust in the salesperson-retailer relationship, which may yield benefits in other aspects of the business relationship and offset the small decrease in commissions. This suggests that in long-term supply chain relationships where trust is vital, job assignments and salesforce incentives that promote a focus on long-term relationships can benefit both the manufacturer and retailer in a supply chain.

In this article, we have focused on trust only in the context of forecast sharing. To develop a more comprehensive understanding of the impact of trust on other aspects of supply chain coordination, further modeling work is needed. For instance, it would be useful to consider a salesperson who performs multiple tasks, possibly including demand promotion and inventory allocation, in addition to forecast sharing, and examine the impact of trust building on the salesperson's effectiveness in the other tasks. It would also be interesting to investigate whether and how the formal contract between the manufacturer and the retailer should change as a function of the social characteristics of the salesperson.

\section{Acknowledgments}

The authors are grateful for the helpful support and guidance of Department Editor Karen Donohue, as well as a senior editor and two anonymous referees. Their questions and suggestions helped us to sharpen and expand our results significantly. We also acknowledge the National Science Foundation, which partially supported this work under grants CMII-0423048 and CMII-0457412.

\section{Notes}

${ }^{1}$ This is because with a linear compensation scheme, the payment of the salesperson is a linear function of the manufacturer's profit and thus the objectives maximizing manufacturer profit and salesperson compensation are aligned.

${ }^{2}$ The reason we need this scale factor is because the retailer and/or manufacturer's profit is usually much larger than that of a salesperson. By adding a scaling factor, we scale down the profit of the retailer and manufacturer so that they are roughly comparable to the salesperson's compensation. Note that the combination of the values $\rho, \theta$, and $\lambda$ is what defines different types of salesperson. Equivalently, one can eliminate the scaling factor $\rho$, and instead consider large values for selfishness parameter $\theta$ (close to 1). In either case, the results of our article are the same.

\section{References}

Anderson, E., A. T. Coughlan. 2002. Channel management: Structure, governance, and relationship management. B. A. Weitz, R. Wensley, eds. Handbook of Marketing. Sage Publications, Thousand Oaks, CA, 223-247.

Aviv, Y. 2001. The effect of collaborative forecasting on supply chain performance. Manage. Sci. 47(10): 1326-1343.

Bendoly, E., K. Donohue, K. L. Schultz. 2006. Behavior in operations management: Assessing recent findings and revisiting old assumptions. J. Oper. Manage. 24(6): 737-752.

Berg, J., J. Dickhaut, K. McCabe. 1995. Trust, reciprocity, and social history. Games Econ. Behav. 10(1): 122-142.

Bohnet, I., R. Zeckhauser. 2004. Trust, risk and betrayal. J. Econ. Behav. Organ. 55(4): 467-484.

Bolton, G. E., A. Ockenfels. 2000. ERC: A theory of equity, reciprocity, and competition. Am. Econ. Rev. 90(1): 166-193.

Cachon, G. P., M. Fisher. 2000. Supply chain inventory management and the value of shared information. Manage. Sci. 46(8): 1032-1048.

Carnevale, P. J. D., A. M. Isen. 1986. The influence of positive affect and visual access on the discovery of integrative solutions in bilateral negotiation. Organ. Behav. Hum. Decis. Proc. 37(1): 1-13.

Charness, G., M. Rabin. 2002. Understanding social preferences with simple tests. Q. J. Econ. 117(3): 817-869.

Chen, F. 2003. Information sharing and supply chain coordination. S. Graves, A. de Kok, eds. Supply Chain Management: Design, Coordination and Operation, Volume 11: Handbooks in Operations Research and Management Science. Elsevier, Amsterdam, 341-421.

Clemen, R., R. Winkler. 1999. Combining probability distributions from experts in risk analysis. Risk Anal. 19(2): 187-203.

Crawford, V. P., J. Sobel. 1982. Strategic information transmission. Econometrica 50(6): 1431-1451.

Crosby, L. A., K. R. Evans, D. Cowles. 1990. Relationship quality in services selling: An interpersonal influence perspective. J. Mark. 54(3): 68-81.

Cui, T. H., J. S. Raju, Z. J. Zhang. 2007. Fairness and channel coordination. Manage. Sci. 53(8): 1303-1314.

Ebrahim-Khanjari, N., S. Iravani, H. Shin. 2011. The impact of the sales-agent's efficiency and demand information on a supply chain. Working paper, Department of Industrial Engineering and Management Sciences, Northwestern University, Evanston, IL.

Engle-Warnick, J., R. L. Slonim. 2004. The evolution of strategies in a repeated trust game. J. Econ. Behav. Organ. 55(4): 553-573. 
Ebrahim-Khanjari, Hopp, and Iravani: Trust and Information Sharing in Supply Chains Production and Operations Management 21(3), pp. 444-464, (c) 2011 Production and Operations Management Society

Fehr, E., K. M. Schmidt. 1999. A theory of fairness, competition, and cooperation. Quarterly J. Econ. 114(3): 817-868.

Ganesan, S. 1994. Determinants of long-term orientation in buyerseller relationships. J. Mark. 58(2): 1-19.

Gachter, S., B. Herrmann, C. Thoni. 2004. Trust, voluntary cooperation, and socioeconomic background: Survey and experimental evidence. J. Econ. Behav. Organ. 55(4): 505-531.

Glaeser, E. L., D. I. Laibson, J. A. Scheinkman, C. L. Soutter. 2000. Measuring trust. Q. J. Econ. 115(3): 811-846.

Handfield, R. B., C. Bechtel. 2002. The role of trust and relationship structure in improving supply chain responsiveness. Ind. Mark. Manage. 31(4): 367-382.

Ho, T. H., N. Lim, C. F. Camerer. 2006. Modeling the psychology of consumer and firm behavior with behavioral economics. J. Mark. Res. 43(3): 307-331.

Hopp, W. J., S. M. R. Iravani, Z. Liu. 2010. The role of salespersons and incentives in supply chain performance. Working paper, Department of Industrial Engineering and Management Sciences, Northwestern University, Evanston, IL.

Kollock, P. 1994. The emergence of exchange structures: An experimental study of uncertainty, commitment, and trust. Am. J. Sociol. 100(2): 313-345.

Kramer, R. M. 1999. Trust and distrust in organizations: Emerging perspectives, enduring questions. Annu. Rev. Psychol. 50(1): 569-598.

Larzelere, R. E., T. L. Huston. 1980. The dyadic trust scale: Toward understanding interpersonal trust in close relationships. J. Marriage Fam. 42(3): 595-604.

Levine, D. K. 1998. Modeling altruism and spitefulness in experiments. Rev. Econ. Dyn. 1(3): 593-622.

Lewicki, R. J., B. B. Bunker. 1995. Trust in relationships: A model of trust and development and decline. B. B. Bunker, J. Z. Rubin eds. Conflict, Cooperation and Justice: Essays Inspired by the Work of Morton Deutsch. Jossey-Bass, San Francisco, CA, 133-174.

Mayer, R. C., J. H. Davis, F. D. Schoorman. 1995. An integrative model of organizational trust. Acad. Manage. Rev. 20(3): 709734.

McAfee, P. R., J. McMillan. 1987. Competition for agency contracts. RAND J. Econ. 18(2): 296-307.

McKnight, D. H., N. L. Chervany. 1996. The meanings of trust. Working paper, University of Minnesota Carlson School of Management, Minneapolis, MN.
McKnight, D. H., L. L. Cummings, N. L. Chervany. 1998. Initial trust formation in new organizational relationships. Acad. Manage. Rev. 23(3): 473-490.

Mellinger, G. D. 1956. Interpersonal trust as a factor in communication. J. Abnorm. Soc. Psychol. 52(3): 304-309.

Moorman, C., G. Zaltman, R. Deshpande. 1992. Relationships between providers and users of market research: The dynamics of trust within and between organizations. J. Mark. Res. 29 (3): 314-328.

Ozer, O., Y. Zheng, K. Chen. 2011. Trust in forecast information sharing. Manage. Sci. 57(6): 1111-1137.

Rabin, M. 1993. Incorporating fairness into game theory and economics. Am. Econ. Rev. 83(5): 1281-1302.

Ren, Z. J., M. A. Cohen, T. H. Ho, C. Terwiesch. 2010. Information sharing in a long-term supply chain relationship: The role of customer review strategy. Oper. Res. 58(1): 81-93.

Rousseau, D. M., S. B. Sitkin, R. S. Burt, C. Camerer. 1998. Introduction to special topic forum: Not so different after all: A crossdiscipline view of trust. Acad. Manage. Rev. 23(3): 393-404.

Smith, K. G., S. J. Carroll, S. J. Ashford. 1995. Intra- and interorganizational cooperation: Toward a research agenda. Acad. Manage. J. 38(1): 7-23.

Stone, M. 1961. The opinion pool. Ann. Math. Stat. 32(4): 1339-1342.

Tardy, C. H. 1988. Interpersonal evaluations: Measuring attraction and trust. C. H. Tardy ed. A Handbook for the Study of Human Communications, Chapter 10. Ablex Publishing, Norwood, NJ, 269-283.

Taylor, T. A., E. L. Plambeck. 2007. Supply chain relationships and contracts: The impact of repeated interaction on capacity investment and procurement. Manage. Sci. 53(10): 1577-1593.

Terwiesch, C., Z. J. Ren, T. H. Ho, M. A. Cohen. 2005. An empirical analysis of forecast sharing in the semiconductor equipment supply chain. Manage. Sci. 51(2): 208-220.

Thompson, L. L. 1991. Information exchange in negotiation. J. Exp. Soc. Psychol. 27(2): 161-179.

Tsay, A. A., N. Agrawal. 2004. Channel conflict and coordination in the e-commerce age. Prod. Oper. Manage. 13(1): 93-110.

Uzzi, B. 1996. The sources and consequences of embeddedness for the economic performance of organizations: The network effect. Am. Sociol. Rev. 61(4): 674-698.

Zaheer, A., N. Venkatraman. 1995. Relational governance as an interorganizational strategy: An empirical test of the role of trust in economic exchange. Strateg. Manage. J. 16(5): 373-392. 